\title{
AerGOM, an improved algorithm for stratospheric aerosol extinction retrieval from GOMOS observations - Part 2: Intercomparisons
}

\author{
Charles Étienne Robert ${ }^{1}$, Christine Bingen ${ }^{1}$, Filip Vanhellemont ${ }^{1}$, Nina Mateshvili ${ }^{1}$, Emmanuel Dekemper ${ }^{1}$, \\ Cédric Tétard $^{1}$, Didier Fussen ${ }^{1}$, Adam Bourassa ${ }^{2}$, and Claus Zehner ${ }^{3}$ \\ ${ }^{1}$ Institut d'Aéronomie Spatiale de Belgique, Brussels, Belgium \\ ${ }^{2}$ Institute of Space and Atmospheric Studies, University of Saskatchewan, Saskatoon, Canada \\ ${ }^{3}$ ESA European Space Research Institute, Frascati, Italy
}

Correspondence to: Charles Étienne Robert (charles.robert@aeronomie.be)

Received: 1 February 2016 - Published in Atmos. Meas. Tech. Discuss.: 16 March 2016

Revised: 5 August 2016 - Accepted: 8 August 2016 - Published: 21 September 2016

\begin{abstract}
AerGOM is a retrieval algorithm developed for the GOMOS instrument onboard Envisat as an alternative to the operational retrieval (IPF). AerGOM enhances the quality of the stratospheric aerosol extinction retrieval due to the extension of the spectral range used, refines the aerosol spectral parameterization, the simultaneous inversion of all atmospheric species as well as an improvement of the Rayleigh scattering correction. The retrieval algorithm allows for a good characterization of the stratospheric aerosol extinction for a wide range of wavelengths.

In this work, we present the results of stratospheric aerosol extinction comparisons between AerGOM and various spaceborne instruments (SAGE II, SAGE III, POAM III, ACE-MAESTRO and OSIRIS) for different wavelengths. The aerosol extinction intercomparisons for $\lambda<700 \mathrm{~nm}$ and above $20 \mathrm{~km}$ show agreements with SAGE II version 7 and SAGE III version 4.0 within $\pm 15 \%$ and $\pm 45 \%$, respectively. There is a strong positive bias below $20 \mathrm{~km}$ at $\lambda<700 \mathrm{~nm}$, which suggests that cirrus clouds at these altitudes have a large impact on the extinction values. Comparisons performed with GOMOS IPF v6.01 alongside AerGOM show that at short wavelengths and altitudes below $20 \mathrm{~km}$, IPF retrievals are more accurate when evaluated against SAGE II and SAGE III but are much less precise than AerGOM. A modified aerosol spectral parameterization can improve AerGOM in this spectral and altitude range and leads to results that have an accuracy similar to IPF retrievals. Comparisons of AerGOM aerosol extinction coefficients with OSIRIS and
\end{abstract}

SAGE III measurements at wavelengths larger than $700 \mathrm{~nm}$ show a very large negative bias at altitudes above $25 \mathrm{~km}$. Therefore, the use of AerGOM aerosol extinction data is not recommended for $\lambda>700 \mathrm{~nm}$.

Due to the unique observational technique of GOMOS, some of the results appear to be dependent on the star occultation parameters such as star apparent temperature and magnitude, solar zenith angle and latitude of observation. A systematic analysis is carried out to identify biases in the dataset, using the various spaceborne instruments as references. The quality of the aerosol retrieval is mainly influenced by the star magnitude, as well as star temperature to a lesser degree. To ensure good-quality profiles, we suggest to select occultations performed with star magnitude $M<2.5$ and star temperature $T>6 \times 10^{3} \mathrm{~K}$. Stray-light contamination is negligible for extinction coefficients below $700 \mathrm{~nm}$ using occultations performed with a solar zenith angle $>110^{\circ}$ but becomes important at larger wavelengths. Comparison of AerGOM results in the tropics shows an enhanced bias below $20 \mathrm{~km}$ that seem to confirm cirrus clouds as its cause. There are also differences between mid-latitude and tropical observations that cannot yet be explained, with a bias difference of up to $25 \%$.

This bias characterization is extremely important for data users and might prove valuable for the production of unbiased long-term merged dataset. 


\section{Introduction}

Stratospheric aerosols are an important part of the Earth system due to their impact on the planet's radiative balance and the crucial role they play in heterogeneous chemistry (Solomon et al., 2011). They can be produced either via binary homogeneous nucleation of $\mathrm{H}_{2} \mathrm{SO}_{4}$ and $\mathrm{H}_{2} \mathrm{O}$ close to the tropical tropopause (so-called background aerosols) or during volcanic eruptions, and form the so-called Junge layer, extending from the tropopause to approximately $35 \mathrm{~km}$ (Junge et al., 1961).

In order to better understand their behaviour and evolution, it is critical to observe these particles globally and over an extended period of time. Various techniques have been employed to retrieve stratospheric aerosols such as solar occultation (e.g. Kent and McCormick, 1984; Thomason et al., 2008; Randall et al., 2001; Thomason et al., 2010; Sioris et al., 2010), balloon-borne measurements (Hofmann et al., 1975; Renard et al., 2002; Deshler et al., 2003), satellite limb sounding (Taha et al., 2011; Bourassa et al., 2007), groundbased lidar (DeFoor et al., 2012; Jäger, 2005), and twilight brightness variation (Mateshvili, 2005).

Another measurement technique, stellar occultation from space, was utilized by the Global Ozone Monitoring by Occultation of Stars (GOMOS). This instrument collected transmission spectra from the Earth's limb in the UV-Vis-NIR, allowing the retrieval of atmospheric profiles from various species, such as $\mathrm{O}_{3}, \mathrm{NO}_{2}, \mathrm{NO}_{3}$, as well as aerosol extinction profiles (Kyrölä et al., 2004; Bertaux et al., 2010). These species are currently retrieved by the latest GOMOS operational data processing algorithm (Kyrölä et al., 2012), hereafter referred to as IPF v6.01.

Recently, a new stratospheric aerosol retrieval algorithm called AerGOM, extensively covered in a companion paper (Vanhellemont et al., 2016), has been applied to the GOMOS transmission data in order to obtain improved stratospheric aerosol profiles. AerGOM is currently the main algorithm used to produce the stratospheric aerosol dataset for the Aerosol Climate Change Initiative (Aerosol_CCI), an ESA project focusing on both tropospheric and stratospheric aerosols (Holzer-Popp et al., 2013).

The purpose of this paper is to assess the agreement and discrepancy between AerGOM stratospheric extinction measurements at different wavelengths and those of various spaceborne instruments that observed the stratosphere in the same spectral range during the Envisat mission, namely SAGE II, SAGE III, POAM III, MAESTRO and OSIRIS. Beside the general comparison between AerGOM and other instruments, the influence of various stellar occultation parameters such as star magnitude and temperature, solar zenith angle as well as the spatio-temporal variability is studied.

\section{The GOMOS instrument}

GOMOS was on-board the successful ESA Environmental Satellite (Envisat) mission. Envisat payloads gathered information about the state of the Earth's atmosphere from shortly after its launch in March 2002 until communication was lost with the satellite in April 2012. The GOMOS instrument functioned almost continuously during its lifetime, except in 2005 when problems with the instrument forced the ground segment team to switch to the redundant measurement system due to errors with the scanning mirrors, impacting measurements during several months (ESA, 2007).

The instrument measured the light transmission from up to 300 stars through the Earth's atmosphere using four spectrometers covering the following spectral regions: 248-371, $387-693,750-776$ and $915-956 \mathrm{~nm}$. The vertical sampling ranges from $200 \mathrm{~m}$ to $1.7 \mathrm{~km}$, depending on the obliquity and the tangent altitude of the observation.

The starlight transmission is not only affected by scattering and absorption but also modified by refractive effects such as chromatic refraction and refractive dilution. More problematic for the analysis of the transmission spectra however is scintillation, i.e. random fluctuations in the measured intensity of stellar light caused by refractive irregularities due to atmospheric instability. Two fast photometers measuring in the blue $(473-527 \mathrm{~nm})$ and the red $(646-698 \mathrm{~nm})$ part of the visible spectrum were used for the scintillation correction and also provided high-resolution temperature profiles (Sofieva et al., 2009).

Beyond these issues, the uncertainty of the retrieval is largely determined by the temperature and magnitude of the observed star. Even bright stars are point sources of lowintensity compared with the sun. Hence, profiles obtained from stellar occultations have larger uncertainties compared with solar occultation measurements. However, this drawback is compensated by the fact that stars are abundant in the sky: $30-40$ occultations per orbit have been typically performed (compared with the 2 occultations available in the case of solar occultation), although this number decreased to 20-30 occultations per orbit after the instrument malfunction in 2005. The retrieval of species using stellar occultation is possible in both bright and dark limb, but in the case of bright limb geometry, the weakness of the signal compared to the ambient light makes the retrieval even more challenging. At this stage, bright limb measurements are not used for the retrieval of stratospheric aerosol extinctions.

\subsection{GOMOS operational stratospheric aerosol retrieval}

The GOMOS operational stratospheric aerosol extinction is retrieved in a two-step process as described in Kyrölä et al. (2010). The first step consists of the spectral inversion, where measured transmittance spectra at each tangent altitude are inverted to slant path integrated column densities/optical thicknesses (for gases and aerosols, respectively). The sec- 
ond step is the spatial inversion, where the slant path columns for each species are inverted to local concentration/extinction profiles. The spatial inversion uses the Tikhonov altitude smoothing technique (Twomey, 1996; Rodgers, 2000) to remove the residual scintillation perturbations in measurements.

The current choice of the Tikhonov parameters leads to the removal of all strong oscillations, at the cost of the vertical resolution, chosen as $4 \mathrm{~km}$ (Vanhellemont et al., 2010).

The specification of the aerosol scattering cross section is difficult since the aerosol content may be very different depending on the state of the atmosphere and the nature of the dominant aerosol mode (background, volcanic, etc.). The current (v6.01) spectral inversion assumes that the stratospheric aerosol extinction obeys a quadratic polynomial as a function of wavelength:

$\beta(\lambda)=\beta_{\text {ref }}\left(c_{0}+c_{1}\left(\lambda-\lambda_{\text {ref }}\right)+c_{2}\left(\lambda-\lambda_{\text {ref }}\right)^{2}\right)$,

where $c_{0}, c_{1}$ and $c_{2}$ are coefficients to be retrieved, and $\lambda_{\text {ref }}$ is a reference wavelength arbitrarily fixed at $500 \mathrm{~nm}$. This is a versatile approach that can represent large and small particle spectra within good approximation. Rayleigh scattering is not retrieved directly from the measurements but removed using external European Centre for Medium-range Weather Forecasts (ECMWF) air density data. This approach sidesteps problems of interferences with the residual scintillation and the spectrally similar aerosol contribution. $\mathrm{NO}_{2}$ and $\mathrm{NO}_{3}$ are retrieved separately using a DOAS approach (Hauchecorne, 2005).

The resulting stratospheric aerosol extinction profiles are of good quality around $500 \mathrm{~nm}$, despite being oversmoothed. At other wavelengths, the profile quality is poor. The main reason for this is that only the coefficient $c_{0}$ is directly smoothed by the Tikhonov approach. This makes the extinction very noisy when departing from the reference wavelength.

Aerosol extinction relative error estimates for bright stars (providing the best signal-to-noise ratio) are of the order of $30 \%$ at $10 \mathrm{~km}, 2-10 \%$ from 15 to $25 \mathrm{~km}$, and $10-50 \%$ from 25 to $40 \mathrm{~km}$ (Vanhellemont et al., 2010). The extinction profiles become increasingly uncertain at lower tangent altitudes because the transmitted light becomes weaker due to increasing atmospheric absorption by gases, aerosols and clouds.

\subsection{AerGOM stratospheric aerosol retrieval}

AerGOM is an improved stratospheric aerosol extinction retrieval method developed for the GOMOS experiment and designed to rectify some of the problems of the operational retrieval, namely the difficulty to obtain proper stratospheric aerosol extinction profiles at $\lambda \neq 500 \mathrm{~nm}$ and the inadequate error characterization of the extinction.

The most important improvements implemented are (1) the extension of the spectral range used for the retrieval using information from spectrometer B1 (755-759, 770-
$775 \mathrm{~nm})$; (2) the refinement of the aerosol spectral parameterization using a second-order polynomial in $\lambda^{-1}$; (3) the simultaneous retrieval of all species $\left(\mathrm{O}_{3}, \mathrm{NO}_{2}, \mathrm{NO}_{3}\right.$, aerosols); (4) a better Rayleigh scattering correction by considering the spectral dependence of the King factor $F_{\text {air }}$ (Bodhaine et al., 1999); and (5) the inclusion of covariances between species after spectral inversion. A detailed description of the algorithm and its improvements is given in a companion paper (Vanhellemont et al., 2016).

The main steps of the AerGOM algorithm are similar to the operational retrieval. First, GOMOS transmittance data are read, along with the ECMWF temperature and pressure profile coincident with the stellar occultation measurements. Based on this data, temperature-dependent gas absorption cross sections are calculated for each tangent height to create the spectral matrix. One can choose either to calculate the Rayleigh scattering contribution based on the ECMWF data or to retrieve it along with the other species. Climatological profiles of various species are provided as a starting point for the non-linear Levenberg-Marquardt spectral inversion, leading to slant path integrated column densities and aerosol optical thicknesses at each tangent height. This is finally followed by a spatial inversion using the Tikhonov approach that leads to local aerosol extinctions, along with the density profiles of the different gaseous species considered. It should be noted that the Tikhonov parameters used for the spatial inversion can be tuned to optimize the removal of residual scintillation. In particular, imposing weak regularization to gaseous species with respect to particulate species leads to noisier profiles for gas concentrations but smoother and more realistic profiles for aerosols.

The improved aerosol spectral law in AerGOM is more flexible since the polynomial can be of any degree and can be based on either $\lambda$ or $\lambda^{-1}$. The formulation as a spectral interpolation formula between a number of discrete extinction coefficients $\beta\left(\lambda_{i}\right)$ that are to be retrieved is also better conditioned and physically more clear than for the operational retrieval.

For the quadratic spectral law, this gives

$\beta_{\text {aero }}(\lambda, r)=\sum_{i=1}^{3} q_{i}(\lambda) \beta_{\text {aero }}\left(\lambda_{i}, r\right)$

with

$q_{i}(\lambda)=\frac{\left(\lambda-\lambda_{j}\right)\left(\lambda-\lambda_{k}\right)}{\left(\lambda_{i}-\lambda_{j}\right)\left(\lambda_{i}-\lambda_{k}\right)}$

with $\lambda_{i}, \lambda_{j}$, and $\lambda_{k}$ different wavelengths to be specified ahead of time.

Given that the aerosol spectral law chosen for the AerGOM processing is of degree $N$, the AerGOM data product consists of extinction values at $N+1$ wavelengths but can be interpolated at other wavelengths using Eqs. (2) and (3). The data used for the current work are based on a quadratic 

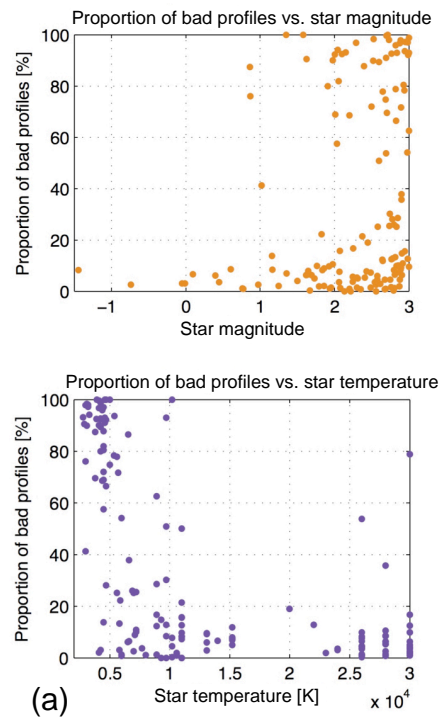

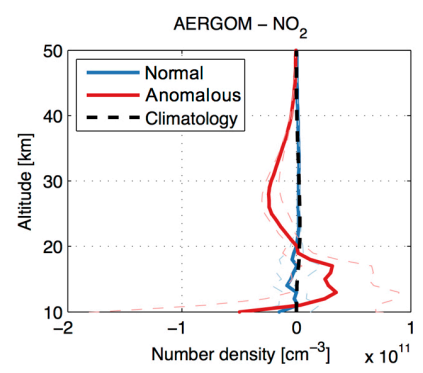

AERGOM $-\mathrm{O}_{3}$

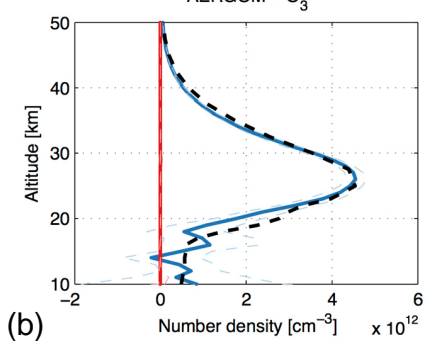

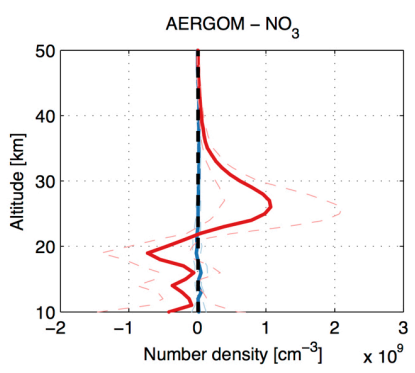

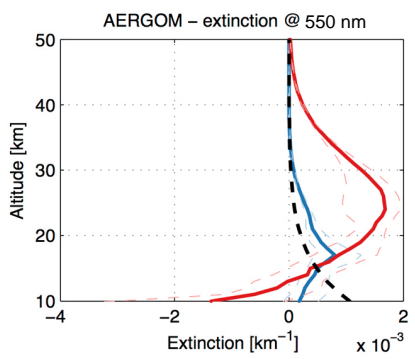

Figure 1. (a) Proportion of anomalous profiles as a function of star temperature and magnitude. (b) Median gas and aerosol extinction profiles for normal and anomalous AerGOM retrievals calculated using 200 profiles.

polynomial in $\lambda^{-1}$ with 350,550 and $750 \mathrm{~nm}$ set as reference wavelengths.

For more details on the AerGOM retrieval algorithm, we refer the interested reader to Sect. 3 of the companion paper (Vanhellemont et al., 2016).

\subsection{Anomalous profiles and stellar occultation parameters}

During the development phase of AerGOM, it was discovered that while the algorithm had beneficial properties regarding the retrieval of stratospheric aerosol profiles, it did have a drawback compared to the operational algorithm, namely that some of the converging retrievals exhibited some non-physical behaviour leading to incorrect retrievals of $\mathrm{O}_{3}, \mathrm{NO}_{2}, \mathrm{NO}_{3}$ and aerosol extinction profiles. These socalled "anomalous profiles" were mostly retrieved for occultations carried out with either a $\operatorname{dim}\left(M_{\text {star }}>2\right)$ and/or a cold $\left(T_{\text {star }}<5 \times 10^{3} \mathrm{~K}\right)$ star, as shown in Fig. 1a. A comparison of gaseous and aerosol profiles between normal AerGOM retrievals and anomalous profiles is shown in Fig. 1b. The data, calculated from the median of 200 profiles, show that anomalous profiles have no ozone, which is compensated above $20 \mathrm{~km}$ by negative $\mathrm{NO}_{2}$ profiles, very large values of $\mathrm{NO}_{3}$ and enhanced aerosol extinction.

The reason for the retrieval of such profiles by AerGOM was due to a combination of low signal-to-noise ratio (SNR) of the transmittance at shorter wavelengths for dim and cold stars, and an inadequate a priori of gaseous and aerosol species. The operational retrieval sidestepped this issue by using first a DOAS method to retrieve $\mathrm{NO}_{2}$ and $\mathrm{NO}_{3}$, removing their contribution from the measured signal before carrying out ozone and aerosol retrieval.
This problem has now been fixed by using full climatologies of gas and aerosol species as a priori for the spectral inversion. However, this finding prompted the consideration that some of the retrievals might be affected by occultation parameters such as star properties and solar zenith angle (SZA) that could lead to stray light, and occultation obliquity which is an important factor in the imperfect correction of atmospheric scintillation (Sofieva et al., 2009). Therefore, another aspect of this intercomparison involves studying the consistency of the agreement of AerGOM aerosol retrievals with those of other instruments under various occultation conditions. Section 6 presents the results of these comparisons.

\section{Intercomparison instruments}

It has been pointed out by Thomason et al. (2010) that aerosol validation is challenging because there is no standard measurement with which to compare. Occultation instruments often validated aerosol data by comparing with each other and a small number of other space-based instruments. A difficulty encountered with this approach is that the aerosol extinction measurements in one experiment do not always have their spectral counterpart in other experiments and cannot be directly compared. Another possibility would be to perform a validation with lidar measurements. Although it could prove useful for periods following volcanic eruptions, it would be non-trivial for periods of low stratospheric aerosol loading, as the corresponding lidar backscatter ratios are too small to convert them to extinction with the required precision and/or accuracy for validation. 
Table 1. Characteristics of the stratospheric aerosol extinction datasets used in this work.

\begin{tabular}{llllll}
\hline Instrument & Version & Host satellite & Measurement method & Time coverage & $\begin{array}{l}\text { Aerosol extinction wave- } \\
\text { length(s) available [nm] }\end{array}$ \\
\hline SAGE II & 7.0 & ERBS & solar occultation & $1984 / 10 / 24-2005 / 08 / 22$ & $386,452,525,1020$ \\
SAGE III & 4.0 & METEOR 3M & solar occultation & $2002 / 02 / 27-2004 / 12 / 02$ & $384,448,520,601,675,755$, \\
& & & & & $869,1022,1545$ \\
POAM III & 4 & SPOT-4 & solar occultation & $1998 / 04 / 22-2005 / 04 / 04$ & $354,439,602,779,922,1020$ \\
MAESTRO & 3.12 .1 & Scisat & solar occultation & $2004 / 02 / 21-$ now & $525,530,560,603,675,779$, \\
OSIRIS & 6 & Odin & limb scattering & $2001 / 10 / 28-$ now & $875,922,995,1012$ \\
GOMOS (IPF) & 6.01 & Envisat & stellar occultation & $2002 / 04 / 15-2012 / 04 / 08$ & $350-750$ \\
GOMOS (AerGOM) & 1.0 & Envisat & stellar occultation & $2002 / 04 / 15-2012 / 04 / 08$ & $350-750$ \\
\hline
\end{tabular}
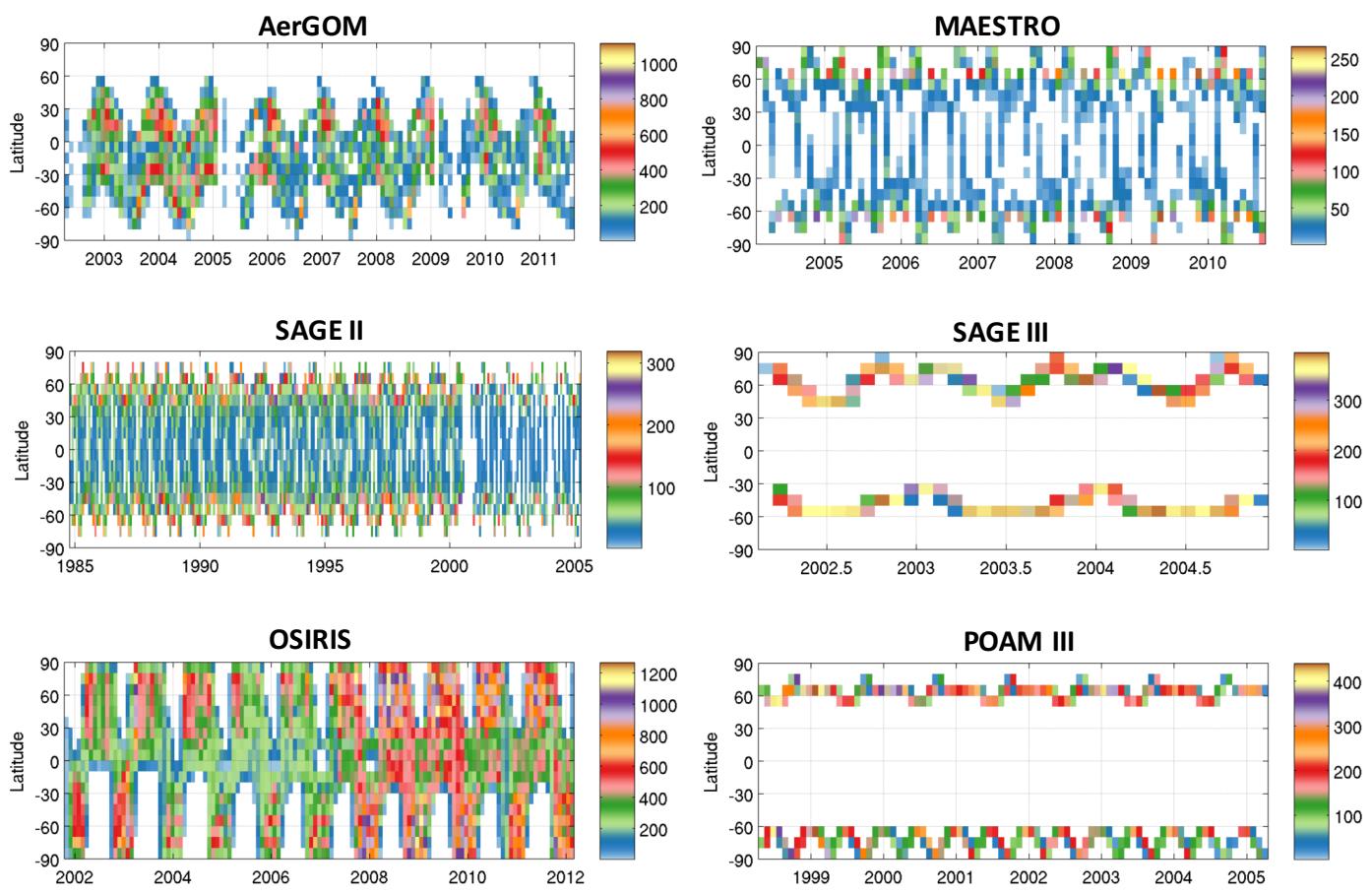

Figure 2. Latitude and temporal coverage for the various instruments used for the intercomparisons. The number of observations per month is calculated for a $10^{\circ}$ latitude bin. The colour code gives the number of observations per month.

In this paper, we opted for the approach of comparing measurements with multiple instruments' datasets. The power of this approach is that by uncovering similar and/or consistent features across the many available measurements, some sort of consensus can be reached on the agreement of the data. The weakness of such methodology is that there is no clear independent source of high-quality information, and consensus does not imply any form of absolute truth.

For this work, the SAGE II, SAGE III, POAM III, MAESTRO and OSIRIS instruments are used as a basis for the intercomparison efforts with AerGOM. Table 1 provides some general information about these instruments and their respective stratospheric aerosol products.

Figure 2 shows the spatio-temporal coverage of the datasets used for this study. Note that the colour scale indi- cating zonally averaged observations per month in a $10^{\circ}$ latitude bin is different for each experiment. There is a vast difference (a factor of 3-4) in coverage from a limb instrument (OSIRIS) compared with solar occultation experiments. GOMOS coverage is more extensive than what is shown in Fig. 2 for AerGOM, but to ensure high-quality data, all observations that could potentially be stray-light-contaminated were filtered out resulting in a limited coverage at high latitudes.

\subsection{SAGE II}

The Stratospheric Aerosol and Gas Experiment (SAGE II) on-board the Earth Radiation Budget Satellite (ERBS) provided high-quality vertical profiles of important atmospheric species from the mid-troposphere through the stratosphere 
during a mission that lasted from October 1984 until August 2005. The instrument recorded the attenuation of sunlight by the Earth's atmosphere in seven spectral channels between 386 and $1020 \mathrm{~nm}$ during each sunrise and sunset encountered by the spacecraft. The measurements were separated into slant path optical depth contributions for $\mathrm{O}_{3}, \mathrm{NO}_{2}, \mathrm{H}_{2} \mathrm{O}$ and aerosol at four channels $(386,452,525$ and $1020 \mathrm{~nm})$ using a least-squares technique (Thomason et al., 2008).

In this work, we use the SAGE II v7.0 stratospheric aerosol dataset (Damadeo et al., 2013) for which the $386 \mathrm{~nm}$ aerosol channel is not recommended due to some unexplained contribution that can be substantial (approaching 30\%) at low extinction levels. Therefore, this channel is not considered in the comparisons. Note also that the aerosol extinction coefficient measurements at $452 \mathrm{~nm}$ do not reliably extend below $12 \mathrm{~km}$ and will not be used below this altitude, whereas measurements made at $525 \mathrm{~nm}$ are reliable in the UTLS and available as low as $5 \mathrm{~km}$ despite substantial impacts by ozone absorption and molecular scattering (Thomason and Vernier, 2013).

\subsection{SAGE III}

SAGE III was launched in December 2001 on-board the Russian METEOR 3M spacecraft. It gathered data from February 2002 until the end of the mission in March 2006, using the technique of solar occultation. It observed the line-ofsight (LOS) transmission profiles from 0.5 to $100 \mathrm{~km}$ at 87 wavelengths from the ultraviolet to the near-infrared with an estimated $0.7 \mathrm{~km}$ vertical resolution.

Aerosol extinction is derived in nine spectral channels by removing the effects of molecular scattering, $\mathrm{O}_{3}$ and $\mathrm{NO}_{2}$ absorption. The precision and accuracy of the aerosol product is linked to the measurement noise in the channel, the quality of the Global Modeling and Assimilation Office (GMAO) density product, the noise and bias in the retrieved $\mathrm{O}_{3}$ and $\mathrm{NO}_{2}$, and the consistency of the cross sections used in the $\mathrm{O}_{3} / \mathrm{NO}_{2}$ multi-linear regression retrieval and those at the aerosol channel wavelengths.

It was found that the aerosol extinction coefficient measurements at $448,520,755,869$, and $1021 \mathrm{~nm}$ are reliable with accuracies and precisions on the order of $10 \%$ in the 15-25 km range (Thomason et al., 2010). It is recommended to only exploit the $385 \mathrm{~nm}$ measurements above $16 \mathrm{~km}$ where the accuracy is on a par with other aerosol channels. Aerosol measurements at 601 and $676 \mathrm{~nm}$ will not be used in the present study because of the large measurement noise of the channel and poor accuracy of the retrieved extinction, respectively.

\subsection{POAM III}

The Polar Ozone and Aerosol Measurement Instrument (POAM III) (Lumpe et al., 2002; Randall et al., 2001) was launched in March 1998 on the Satellite Pour l'Observation de la Terre (SPOT 4) in a sun-synchronous polar orbit.

The instrument used the solar occultation technique to measure atmospheric transmission across nine spectral channels in the UV-Vis range. From these measurements, $\mathrm{O}_{3}$, $\mathrm{NO}_{2}, \mathrm{H}_{2} \mathrm{O}$ and $\mathrm{O}_{2}$ vertical profiles can be retrieved. Stratospheric aerosols are also retrieved at several wavelengths $(354,439,602,778,922,1020 \mathrm{~nm})$ up to an altitude of approximately $25 \mathrm{~km}$.

POAM III sunrise aerosol extinction measurements at both 1020 and $450 \mathrm{~nm}$ are within $\pm 30 \%$ of SAGE II. However, POAM III exhibits a significant sunrise-sunset bias in its extinction measurements that leads to poorer agreement between SAGE II and the POAM III sunset data. This is important for this work since collocations with GOMOS observations are only found for POAM III sunset occultations. POAM III sunset aerosol extinctions at $1020 \mathrm{~nm}$ and $440 \mathrm{~nm}$ both exhibit a positive bias with respect to SAGE II, whose magnitude changes with altitude but can be as large as $50 \%$.

\subsection{MAESTRO}

The Atmospheric Chemistry Experiment (ACE) mission (Bernath et al., 2005) was launched on 12 August 2003 onboard the SCISAT satellite and is still currently operational. The satellite is in a low-Earth circular orbit at an altitude of $650 \mathrm{~km}$ and $74^{\circ}$ inclination. The ACE mission is comprised of two instruments: a Fourier transform spectrometer (ACE-FTS) and the Measurement of Aerosol Extinction in the Stratosphere and Troposphere Retrieved by Occultation instrument (MAESTRO) (McElroy et al., 2007, 2013). The MAESTRO instrument uses the solar occultation technique and is made of two independent spectrophotometers, one measuring in the UV $(285-550 \mathrm{~nm}, 1.5 \mathrm{~nm}$ spectral resolution) while the other observes in the VIS-NIR spectral region $(525-1020 \mathrm{~nm}, 2 \mathrm{~nm}$ spectral resolution). These measurements allow the retrieval of atmospheric species such as $\mathrm{O}_{3}, \mathrm{NO}_{2}, \mathrm{H}_{2} \mathrm{O}, \mathrm{O}_{2}$ and aerosols. Measurements are made at tangent altitudes between 0 and $150 \mathrm{~km}$ (using measurements between 100 and $150 \mathrm{~km}$ to determine the sun reference spectrum) and allow for a best-case vertical resolution of $1.2 \mathrm{~km}$ at a tangent height of $22 \mathrm{~km}$. The aerosol extinction is retrieved at 525, 530, 560, 603, 675, 779, 875, 922, 995 and $1012 \mathrm{~nm}$ wavelengths. Cirrus clouds are not filtered from the dataset.

Though able to retrieve high-resolution aerosol extinction profiles, MAESTRO has two issues affecting its measurements: (1) an altitude assignment problem that can lead to outlier data and (2) an unidentified problem (suspected to be a dark count model issue) that makes small optical depths too large. 


\subsection{OSIRIS}

The Optical Spectrograph and InfraRed Imaging System (Llewellyn et al., 2004), on-board Odin, measures the vertical distribution of atmospheric limb radiance spectra. The satellite was launched in February 2001 in a sun-synchronous polar orbit and continues full operation at the time of writing. The local time of the ascending node is 18:00 LT, providing measurements of the sunlit summer hemisphere, global measurements during equinox, and a limited coverage of the winter hemisphere.

The two sub-systems of OSIRIS are an optical spectrograph (OS) and an infrared imager (IRI). The optical spectrograph consists essentially of a grating and a CCD detector, and measures the limb radiance spectra from 280 to $800 \mathrm{~nm}$ with a spectral resolution of approximately $1 \mathrm{~nm}$ (Bourassa et al., 2007). The sampling resolution of the measurements is approximately $2 \mathrm{~km}$.

The IRI is composed of three vertical near-infrared channels that capture one-dimensional images of the limb radiance at $1.26,1.27$, and $1.53 \mu \mathrm{m}$ at a tangent altitude resolution of approximately $1 \mathrm{~km}$. OSIRIS aerosol data product version 5 is derived using only the optical spectrograph measurements, and an alternate dataset (version 6) exploits both instruments for the retrieval of the aerosol extinction profiles (Rieger et al., 2014), allowing a better characterization of the aerosol scattering phase function and improving the retrieval substantially. The drawback of this new approach is that retrievals are noisier and have a tendency to saturate at low altitudes and high aerosol loadings such as in the centre of volcanic plumes. It is this latest version (v6) of the OSIRIS dataset that is used in this study. However, the comparison results presented in this paper can be generalized to OSIRIS aerosol extinction v 5 dataset at $750 \mathrm{~nm}$, as there are very little differences between both datasets when it comes to AerGOM comparisons.

It is important to note that the OSIRIS dataset 66 is based on measured radiances at 750 and $1530 \mathrm{~nm}$, from which an Ångström exponent is derived. In this work, we perform comparisons with OSIRIS extinction at $750 \mathrm{~nm}$ but also at wavelengths outside the range used to determine the Ångström exponent ( 350 and $550 \mathrm{~nm})$.

\section{Methodology}

The comparison of datasets is based on the statistical analysis of collocated events, defined here as observations within a distance $\Delta r=500 \mathrm{~km}$ and a period $\pm \Delta t=12 \mathrm{~h}$ from each other. Since stratospheric aerosols are assumed to be slowly varying over time and space in the absence of volcanic activity, these criteria are deemed acceptable. It should be noted that processes such as pyro-convective events, other tropospheric intrusions and polar stratospheric clouds can also significantly change the extinction signal in the stratosphere and therefore make it more difficult to compare data points that are further apart. The key is to strike a balance between the proximity of observations in time and space and the number of sample observations available for analysis. Evaluation of different collocation criteria showed that constraining further the $\Delta t$ and $\Delta r$ generally does not affect the final results but sometimes lead to undersampling.

The relative difference between the AerGOM extinction $\beta_{\text {AerGOM }}$ and the extinction from a collocated measurement $\beta_{i}$ from dataset $i$ (in $\%$ ) is

$100 \times\left(\frac{\beta_{\mathrm{AerGOM}}-\beta_{i}(\lambda)}{\beta_{i}(\lambda)}\right)$.

All observations with a relative uncertainty larger than $100 \%$ are discarded before performing the analysis in order to avoid biasing the results due to inferior quality data, but it should be noted that using all observations does not alter the results significantly. The profiles are interpolated on a common $1 \mathrm{~km}$ spacing vertical grid using a linear interpolation method. AerGOM extinctions are interpolated at the wavelength(s) of the other instruments using Eq. (2). In this way, a distribution of values is obtained for each tangent altitude $z$ and wavelength $\lambda$ and the final results are derived from this distribution by calculating the interquartile mean and the semi-interquartile range, which should be robust estimates of the average value and the variability, respectively.

\section{Comparison of collocated profiles}

Figure 3 shows the results of the intercomparison of AerGOM against all datasets from Table 1 using the method outlined in Sect. 4. Three different aspects of the comparison are shown: the relative difference (interquartile mean), the relative difference variability (semi-interquartile range), and the absolute aerosol extinction profiles of AerGOM and the other datasets (interquartile mean). The total number of collocations is also indicated and varies widely from one dataset to the next. To quantify the effect of the change in retrieval algorithm from IPF to AerGOM, the comparisons were also performed using IPF and the results are shown as dashed lines in the relative difference and the variability plots.

\subsection{AerGOM comparison with other datasets}

Overall, the agreement between AerGOM and other datasets for tangent altitudes between 15 and $30 \mathrm{~km}$ is typically within $\pm 50 \%$ for extinctions in the $400-600 \mathrm{~nm}$ spectral range. The comparison with SAGE II between 20 and $30 \mathrm{~km}$ shows good results, with a bias within $\pm 15 \%$, which is close to the reported $10 \%$ accuracy and precision of SAGE II for these altitudes. Results for comparisons between AerGOM and SAGE III are not as good, with mostly positive biases that vary from $-10 \%$ at $20 \mathrm{~km}$ up to $40 \%$ at $30 \mathrm{~km}$, depending on the wavelength. This bias is larger than the expected precision and accuracy of the SAGE III instrument $(10 \%$ up to 

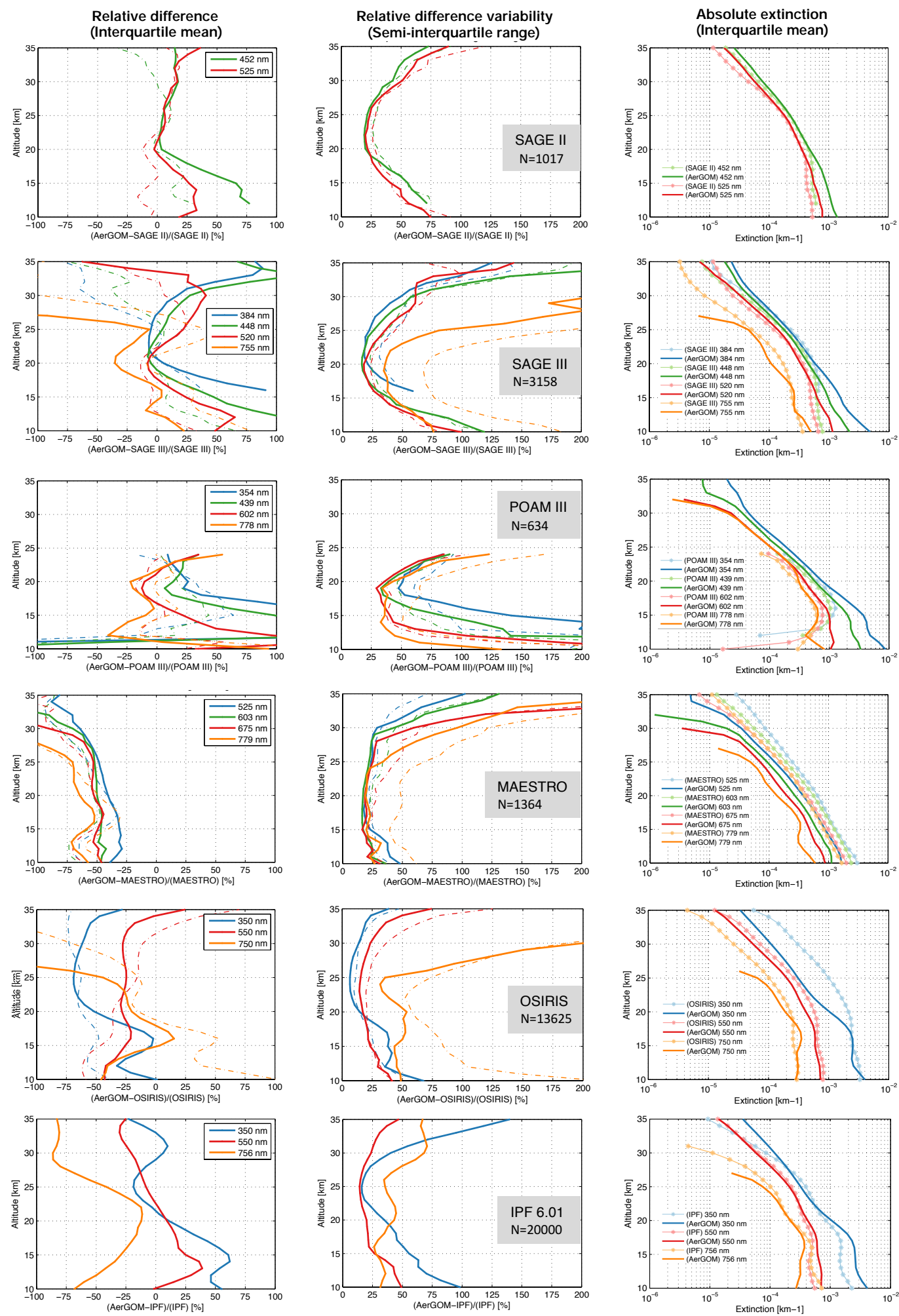

Figure 3. Relative difference (left panels), variability of the relative difference (central panels) and absolute aerosol extinction vertical profiles (right panels) for each dataset (SAGE II, SAGE III, POAM III, MAESTRO, OSIRIS and IPF) at various wavelengths compared with collocated AerGOM profiles. The dashed curves in the relative difference plots were calculated using IPF v6.01 instead of AerGOM. The total number of collocated profiles $N$ is also indicated. 
$25 \mathrm{~km}$ ), indicating potential issues with the data. It is also surprising that the $520 \mathrm{~nm}$ extinction is the most biased within this altitude and spectral range, as one would expect it to be most accurate for AerGOM.

According to the work of Damadeo et al. (2013), the $525 \mathrm{~nm}$ aerosol extinction measurements from SAGE II version 7.0 and SAGE III version 4.0 should agree to within a few percent. It is therefore puzzling to see such differences in the intercomparisons of AerGOM with both instruments. The reason for the discrepancy is that the SAGE II and SAGE III data are not sampled in the same way when it comes to AerGOM collocations, with SAGE III data found solely in the southern hemispheric mid-latitudes, whereas collocations with SAGE II measurements are found at all latitudes. Results from Sect. 6.3 show that the bias varies based on the latitude of observation, and when comparing results from the same latitude bands, the intercomparisons are consistent with the results from Damadeo et al. (2013). For POAM III comparisons below $700 \mathrm{~nm}$ and above $20 \mathrm{~km}$, biases are similar to what is seen in SAGE III but shifted by $15 \%$.

Below $20 \mathrm{~km}$, comparisons between AerGOM extinction at shorter $(\lambda<700 \mathrm{~nm})$ wavelengths and SAGE II, SAGE III and POAM III extinctions show a strong positive bias, increasing with decreasing altitude. This positive bias is larger for shorter wavelengths. These features could be the result of subvisible cirrus clouds present in the field of view, but it is unclear why only these datasets are affected while comparisons with MAESTRO and OSIRIS show no such large positive biases, and why the effect is much more pronounced in the case of AerGOM than for comparisons with IPF. The latter result suggests that the AerGOM retrieval algorithm itself must be the cause of this bias, not the GOMOS instrument, despite its known decreasing SNR with decreasing tangent altitude. Section 6.3 takes a closer look at the potential effect of clouds on the results from the perspective of latitude of observation.

The results of the comparison between AerGOM and MAESTRO extinction profiles at shorter $(\lambda<700 \mathrm{~nm})$ wavelengths show a different behaviour of the relative difference than seen in the other comparisons. AerGOM is negatively biased compared with MAESTRO, with values of the biases ranging from -35 to $-50 \%$. The bias is quite constant within an altitude range of 10 to $25 \mathrm{~km}$. Above $25 \mathrm{~km}$, all AerGOM extinctions become increasingly negatively biased with regards to MAESTRO with increasing altitude and wavelength. These results seem to confirm the issues suspected with the MAESTRO dataset, namely that it retrieves too large aerosol extinctions. Based on the AerGOM comparison, this effect increases with the wavelength of observation. One surprising feature of the comparison is the small variability $(25 \%)$ of the relative difference with AerGOM, almost constant between 10 and $25 \mathrm{~km}$ and for all wavelengths.

OSIRIS data at wavelengths below $750 \mathrm{~nm}$ are extrapolated and should be used cautiously, but it is nevertheless interesting to see that there is a pretty good agreement be- tween AerGOM and OSIRIS at $550 \mathrm{~nm}$, with an almost constant negative bias of $25 \%$ between 15 and $30 \mathrm{~km}$. For shorter wavelengths however, the comparison shows that OSIRIS extinctions are much larger than AerGOM above $20 \mathrm{~km}$.

Looking at comparisons of AerGOM aerosol extinction profiles for $\lambda>700 \mathrm{~nm}$, one can see that there is clearly a problem with AerGOM results at larger wavelengths, despite the use of GOMOS transmission data from spectrometer B1 that should have improved the aerosol retrieval in this spectral region. There is a strong negative bias above 25-30 km with respect to all other datasets (especially clear with SAGE III, MAESTRO and OSIRIS) that increases towards higher altitudes. Above $27 \mathrm{~km}$, retrieved extinctions at $\lambda>700 \mathrm{~nm}$ are mostly negative, hence the large negative biases observed. These large discrepancies could very well be due to the use of outdated ozone cross sections. It was mentioned in Thomason et al. (2010) that anomalous aerosol extinctions in the SAGE III $755 \mathrm{~nm}$ channel from previous versions of the dataset were caused by the use of an outdated ozone cross section that had errors of the order of $10 \%$ in the Chappuis band. Preliminary work to improve the trace gas cross sections used with AerGOM seems to confirm that such changes can lead to a significant improvement of the aerosol extinction values for $\lambda>700 \mathrm{~nm}$, especially above $25 \mathrm{~km}$. Looking at the AerGOM absolute extinction profiles at $\lambda>700 \mathrm{~nm}$, one notices that there are more vertical structures than for the other wavelengths, with a small peak around $16 \mathrm{~km}$, and troughs near 13 and $20 \mathrm{~km}$. Interestingly, these structures are also seen in the comparison results with IPF at all wavelengths and, hence, seem to be somewhat linked to the measurement method or to some aspect of the retrieval that is common to both AerGOM and IPF algorithms.

The variability of the extinction comparisons in the 350$600 \mathrm{~nm}$ spectral range increases with decreasing tangent altitudes and is larger for shorter wavelengths. This is expected, as it simply follows the spatial and spectral behaviour of the GOMOS SNR, and is confirmed by the similar IPF comparison variability. The dispersion of the comparisons at $\lambda>700 \mathrm{~nm}$ is less systematic but tends to increase dramatically with tangent altitudes above $20-25 \mathrm{~km}$, correlated with the strong negative bias.

For reference purposes, we also show the comparison between AerGOM and IPF profiles in the bottom panel of Fig. 3. The results are based on 20000 randomly chosen GOMOS observations spanning different geolocations and occultation parameters. Even though the raw data come from the same instrument, the comparison shows substantial differences.

\subsection{Differences between AerGOM and IPF}

Figure 3 also displays the results of the comparisons with regards to IPF, and it is surprising to see that in some instances, these results are not clearly favouring AerGOM over 

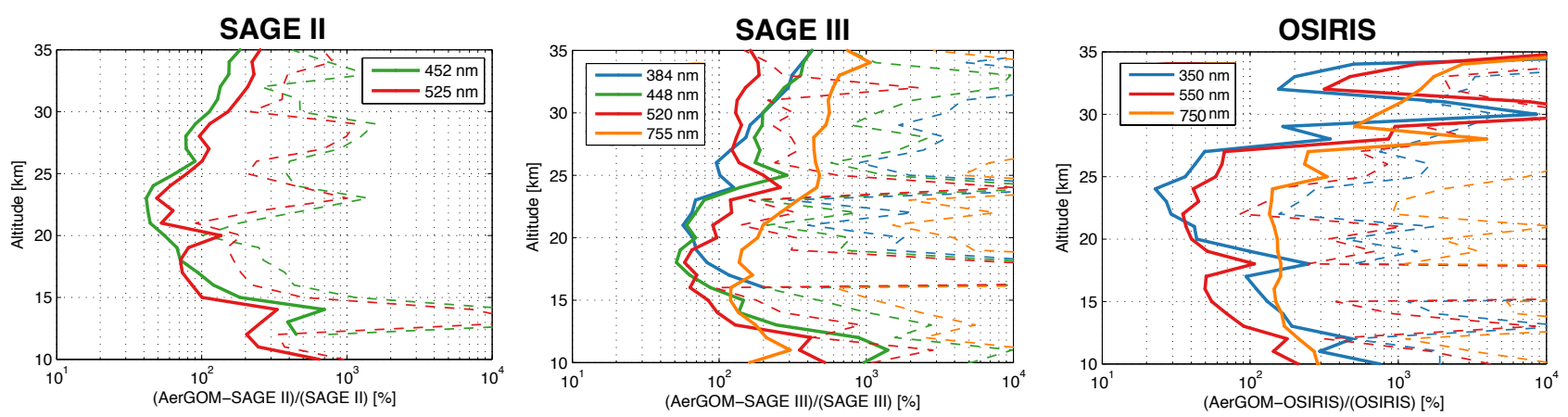

Figure 4. Standard deviation of the aerosol extinction relative difference for AerGOM (solid) and IPF (dashed) comparisons with SAGE II, SAGE III and OSIRIS. Note that the abscissa is scaled logarithmically.

IPF. In several cases (SAGE II, SAGE III and POAM III) and more specifically for observations below $20 \mathrm{~km}$ and for $\lambda<700 \mathrm{~nm}$, the IPF results are in better agreement with the correlative measurements than AerGOM, giving rise to the question of whether AerGOM can be considered an improvement over IPF.

Vanhellemont et al. (2016) show that the conceptual improvements of AerGOM are translated into aerosol extinction profiles that are better behaved than those of IPF v6.01, with AerGOM results being particularly less noisy than their IPF counterparts and having a more realistic spectral dependence. However, since the present work averages a large number of profiles to obtain the results and does so in a robust way by using the interquartile mean and the semi-interquartile range as a metric of the central tendency and dispersion, respectively, the noise in the IPF data is no longer a concern. Therefore under certain conditions, despite the fact that the IPF v6.01 aerosol dataset is noisier and hence less precise, it is more accurate than AerGOM.

One of the great strengths of AerGOM however is its higher precision, which is quantified in the variability. It can already be seen from Fig. 3 that the variability of AerGOM comparison results is typically smaller than those made with IPF, especially between 15 and $30 \mathrm{~km}$. Then again, these results are only based on $50 \%$ of the data. If instead of the semi-interquartile range, one uses the standard deviation as a measure of the variability, consequently using the entire distribution of data, the real advantage of AerGOM over IPF becomes clear. Figure 4 shows the standard deviation of the relative difference on a logarithmic scale for comparisons of AerGOM (solid) and IPF (dashed) with SAGE II, SAGE III and OSIRIS as a function of altitude. Not only is the dispersion of IPF results larger than those of AerGOM below $30 \mathrm{~km}$, it is not uncommon for it to be more than an order of magnitude larger. The variability of the IPF comparisons becomes larger as the wavelength considered is far from $500 \mathrm{~nm}$, the reference wavelength for the spectral model used in IPF.
Of course, one would hope that a dataset is both precise and accurate, and it is meaningful to search for ways to improve the current AerGOM dataset so that it agrees better with SAGE II and SAGE III, both considered excellent aerosol extinction datasets. There are several ways in which the AerGOM algorithm settings can be modified to improve its retrieval of stratospheric aerosols such as using improved trace gas absorption cross sections or using a full covariance matrix when performing the inversion. But one particular aspect of AerGOM seems to have a large effect on the aerosol extinction in the UTLS, namely the aerosol spectral law chosen to model the aerosol extinction cross section. The current version of AerGOM uses a second-degree polynomial in $\lambda^{-1}$, but some preliminary results show that using a polynomial of degree 1 instead significantly improves the results below $20 \mathrm{~km}$. These results are shown in Fig. 5, where a modified AerGOM algorithm using a polynomial of degree 1 in $\lambda^{-1}$ as spectral law was used to generate a new dataset that was then compared with SAGE II and SAGE III. The improvements below $20 \mathrm{~km}$ are clear, with biases being limited to within $25 \%$ above $12 \mathrm{~km}$ for SAGE II, and within $\pm 50 \%$ for SAGE III. While more work is needed, this seems to show that slight modifications to the algorithm settings can lead to results that are more in line with those of the SAGE instruments.

\section{Bias variability with star and occultation parameters}

Section 5 described AerGOM's bias relative to other instruments, but it did not take into account the very specific features of GOMOS which do not concern the other sensors but may dramatically affect the quality of AerGOM extinction. Specifically, the use of a wide range of stellar sources with very different characteristics, the subsequent low value of the SNR, and the versatility of the occultation configuration reflected in the obliquity and the solar zenith angle may all affect the GOMOS measurements.

The purpose of this section is to perform a more detailed analysis and assess whether occultation parameters may affect the extent and consistency of the bias between Aer- 

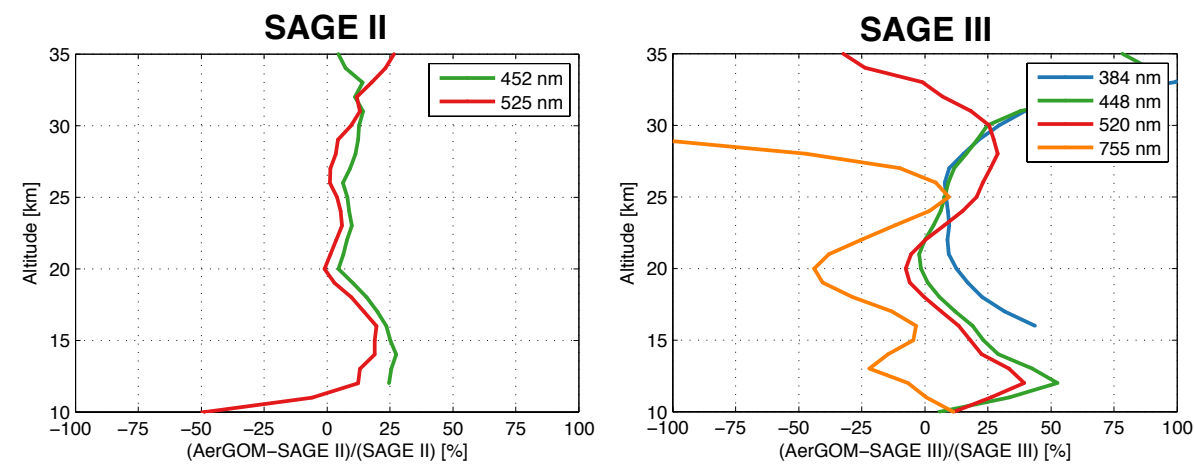

Figure 5. Relative difference of aerosol extinction comparisons between a modified AerGOM dataset using a different spectral law (polynomial of degree 1 in $\lambda^{-1}$ ) and SAGE II and SAGE III datasets at different wavelengths. These results show a better agreement between AerGOM and both SAGE instruments below $20 \mathrm{~km}$.

GOM and other instruments. For each instrument, comparisons were carried out as explained in Sect. 4, except that only a specific subset of collocated profiles corresponding to particular criteria was used to calculate the interquartile mean. The parameters under investigation are star properties, solar zenith angle and latitude of observation. A study of the effect of the obliquity on the bias was carried out, but the results did not bear any concluding evidence of a repercussion on the AerGOM measurements and were therefore omitted from the discussion. Note that this analysis is only valid for the AerGOM retrieval and cannot be generalized to the IPF dataset. Due to the very large variability of the comparisons between POAM III and AerGOM observed in the last section, POAM III results are not included in this part of the work.

Studying the effects of a given occultation parameter or star property assumes that only one variable will change while all other parameters are constant, but this is not always the case for GOMOS. Most parameters are somewhat interdependent, albeit very loosely in some cases. Figure 6 gives an overview of the interdependence of several parameters: star magnitude, star temperature, latitude and SZA. The figure shows 2-D histograms of the number of observations for different combinations of these occultation parameters, taking into account only dark limb GOMOS observations. From these graphs, one can see for instance that at low SZA $\left(\leq 120^{\circ}\right)$, almost no bright stars are available and mostly only dim stars will be used for occultation. Maybe the clearest and most important dependence among the occultation parameters is observed for solar zenith angles and latitudes of observations, where low SZA values correspond to high latitudes and equatorial observations to high SZA values. We must therefore be cautious when analysing the results of comparisons with regards to certain occultation parameters and take into account this interdependence.
Table 2. Classes of star properties (as defined in this work).

\begin{tabular}{|c|c|c|c|}
\hline $\begin{array}{c}\text { Star temperatures } \\
10^{3} \mathrm{~K}\end{array}$ & Descriptor & $\begin{array}{r}\text { Star } \\
\text { magnitudes }\end{array}$ & Descriptor \\
\hline $0-6$ & cold & $-1.5-1.5$ & bright \\
\hline $6-26$ & mid-cold & $1.5-2.3$ & mid-bright \\
\hline $26-40$ & hot & $2.3-3$ & $\operatorname{dim}$ \\
\hline
\end{tabular}

\subsection{Star properties}

The properties of stars (star temperature $T_{\text {star }}$ and magnitude $M_{\text {star }}$ ) used as light source by GOMOS largely determine the shape of its spectral irradiance: cold (hot) stars have larger spectral irradiance at longer (shorter) wavelengths. In addition, the magnitude of the star might mitigate or aggravate the impact of the shape of the spectral irradiance on the quality of the retrieval by altering further the SNR in different spectral regions. In particular, it could be expected that dim stars seriously affect results at short (long) wavelengths for cold (hot) stars. Table 2 details the nine distinct categories of stars that we have defined for this work and that we will consider, ranging from dim and cold to hot and bright.

Figure 7 presents the results of the comparisons between AerGOM and the other datasets at various wavelengths and according to the defined star classes. The rightmost panel shows the number of observations available to perform the comparisons. Note that in some cases, the number of observations is very limited so that the effects seen in these cases may be strongly affected by subsampling.

There is a clear departure from the consensus across the various experiments at long wavelengths $(>700 \mathrm{~nm})$ for $\mathrm{dim}$ and hot star occultations. More particularly, the effect is visible for occultations using stars with $M_{\text {star }}>1.5$, except for cold stars. In these cases, AerGOM is more negatively biased than usual, starting around $25 \mathrm{~km}$ and worsening towards lower altitudes. The star magnitude plays a major role on the bias variability for hot stars. Case in point, for the 

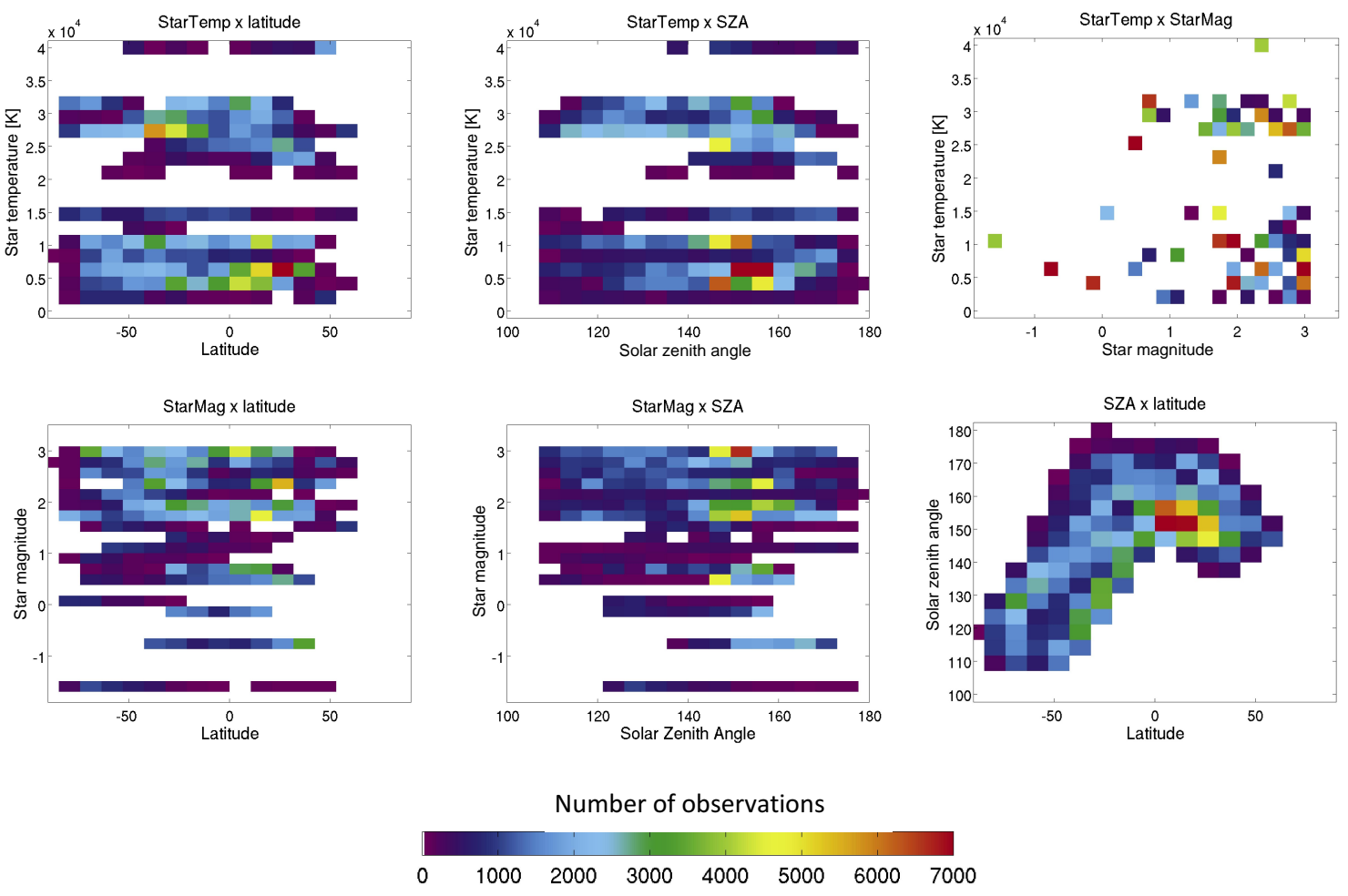

Figure 6. Interdependence of the GOMOS occultation parameters depicted using 2-D histograms of the number of observations for different combinations of occultation parameters (star temperature and magnitude, solar zenith angle and latitude of observation).

AerGOM-OSIRIS comparison at $750 \mathrm{~nm}$, the bias can vary from $-300 \%$ for dim-hot stars to $+50 \%$ for bright-hot stars at $17 \mathrm{~km}$.

The occultation star properties have the largest influence on AerGOM extinctions when considering dim-hot stars, especially for AerGOM aerosol extinction at wavelengths larger than $650 \mathrm{~nm}$. The effect can also be seen at $550 \mathrm{~nm}$ but to a more limited extent. For SAGE II (452, $525 \mathrm{~nm})$, SAGE III $(520 \mathrm{~nm})$, MAESTRO $(525 \mathrm{~nm})$ and OSIRIS $(550 \mathrm{~nm})$, AerGOM is more negatively biased between approximately 15 and $20 \mathrm{~km}$.

At shorter wavelengths $(<400 \mathrm{~nm})$, the AerGOM comparison for cold star occultations also shows a different behaviour with respect to the other star property comparisons, but the effect is much less dramatic and not consistent across the various datasets. For SAGE III, dim-cold star occultations are very negatively biased between 17 and $23 \mathrm{~km}$ with regards to the other occultations but are positively biased between 25 and $35 \mathrm{~km}$. Overall, in this short wavelength range, the weakness of the signal from dim-cold stars is responsible for the erratic behaviour of the bias profile at the lowest altitudes toward the troposphere.

\subsection{Solar zenith angle}

Another parameter studied is the solar zenith angle at which the stellar occultation was carried out. SZA is an indicator of the local time, although there is no reason to believe that this can affect the extinction comparisons. Here, we assume that the dependence of the AerGOM results on the SZA, if any, is due to stray light as there is a larger probability that stray light finds its way into the instrument as the SZA decreases.

The AerGOM aerosol retrieval is only carried out for observations made in partially or completely dark limb, meaning that the SZA of observations will vary between 100 and $180^{\circ}$. There is already a stray-light correction applied to GOMOS Level 1 product, but an evaluation of the AerGOM dataset seems to show some residual stray-light contamination in the data.

Figure 8 shows the results of the comparisons between AerGOM and other datasets according to different values of the SZA. The common feature to these comparisons is that AerGOM is indeed more negatively biased for low SZA, but this is only clearly visible for wavelengths larger than $600 \mathrm{~nm}$. The impact of the SZA on the bias seems to be progressive, which is clear when looking for instance at the AerGOM-OSIRIS comparisons at $750 \mathrm{~nm}$. The SZA impacts the comparisons mostly above $15 \mathrm{~km}$, although this could be linked to poor sampling below that tangent altitude. The effect of the SZA on the comparisons at wavelengths around below $600 \mathrm{~nm}$ seems to be minor for most altitude of observations but gains in importance above $27 \mathrm{~km}$. 

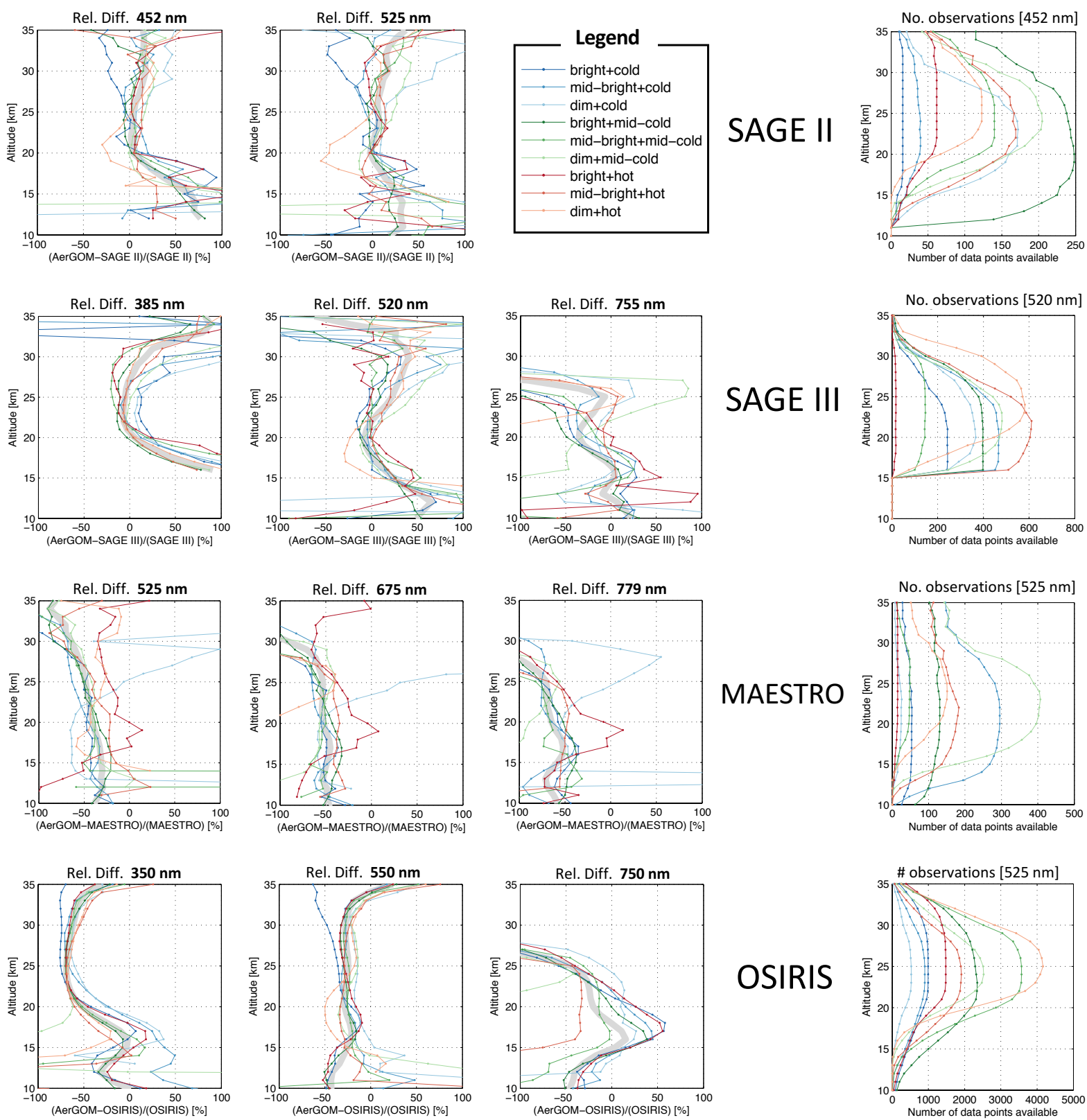

Figure 7. Relative differences between AerGOM and SAGE II, SAGE III, MAESTRO and OSIRIS datasets for different star categories, ranging from dim-cold to bright-hot (left panels). The rightmost panel presents the number of observations for each dataset comparison and star category.

These results strongly suggest the presence of stray light, as it should increase the number of photons detected by the spectrometer, hence artificially increasing the value of the transmission and decreasing the retrieved extinction. If this decrease in extinction is attributed to the aerosol (which has a slow varying spectral dependence unlike ozone, $\mathrm{NO}_{2}$ and $\mathrm{NO}_{3}$ ), then the comparison should show a decrease of the positive bias. If we assume the stray light to be more or less constant with altitude, its relative effect should be larger at high altitudes $(>25 \mathrm{~km})$ and longer wavelengths, due to the generally much smaller aerosol extinction values typically found for such cases.

\subsection{Latitude}

The latitude of the occultation can strongly affect comparisons, especially because cloud phenomena are involved. At high latitudes, polar stratospheric clouds (PSCs) can affect the mean extinction profiles if not filtered out, while in the tropics and mid-latitudes, high-altitude cirrus clouds can 

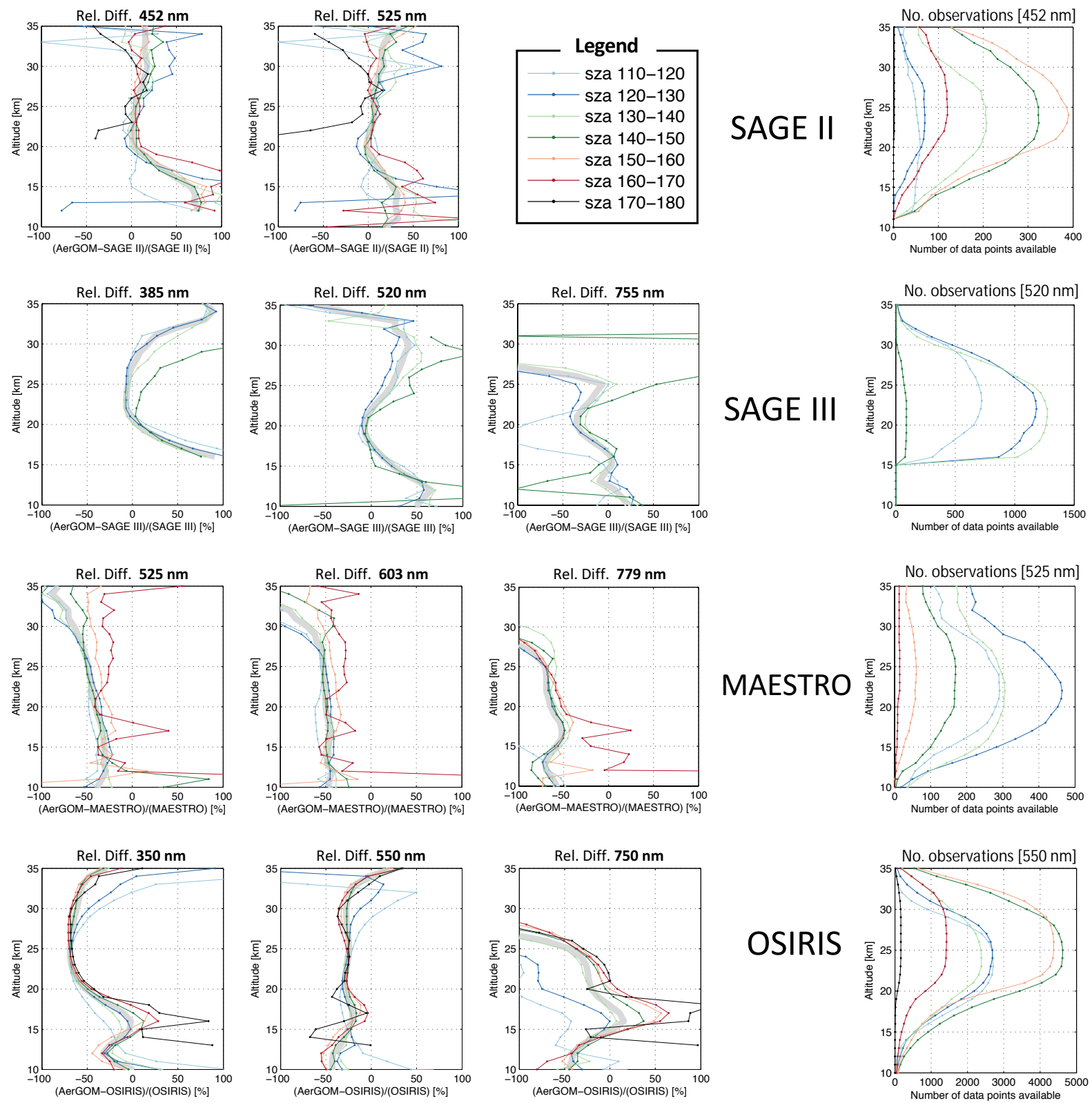

Figure 8. Relative differences between AerGOM and SAGE II, SAGE III, MAESTRO and OSIRIS datasets for different categories of SZA, ranging from 110 to 180 in $10^{\circ}$ increments (left panels). The rightmost panel presents the number of observations for each comparison and SZA category.

have an impact on the lower stratospheric extinction. Note that, for the comparisons performed in this work, no filtering of cirrus clouds or PSCs was carried out. It should also be mentioned that there could be an indirect effect of the latitude on the extinction profiles due to the strong correlation between SZA and latitude (see Fig. 6). The influence of SZA on the extinction has already been examined in Sect. 6.2.

Figure 9 shows that, for SAGE II, MAESTRO and OSIRIS, there are some effects on the comparisons pertaining to the latitudes at which the occultations were made.
The most prominent effect is seen in the tropics, for latitudes between -30 and $30^{\circ}$, where the comparisons show an increased bias between 15 and $20 \mathrm{~km}$ at all wavelengths. Interestingly, von Savigny et al. (2015) also reported similar biases in the lower stratosphere when comparing SCIAMACHY and SAGE II stratospheric aerosol extinction, although the bias increased with decreasing altitudes. This seems to indicate that cirrus clouds do have an impact on the comparisons. For OSIRIS, the aerosol data are not cloud filtered per se but they do provide a dataset that is restricted 

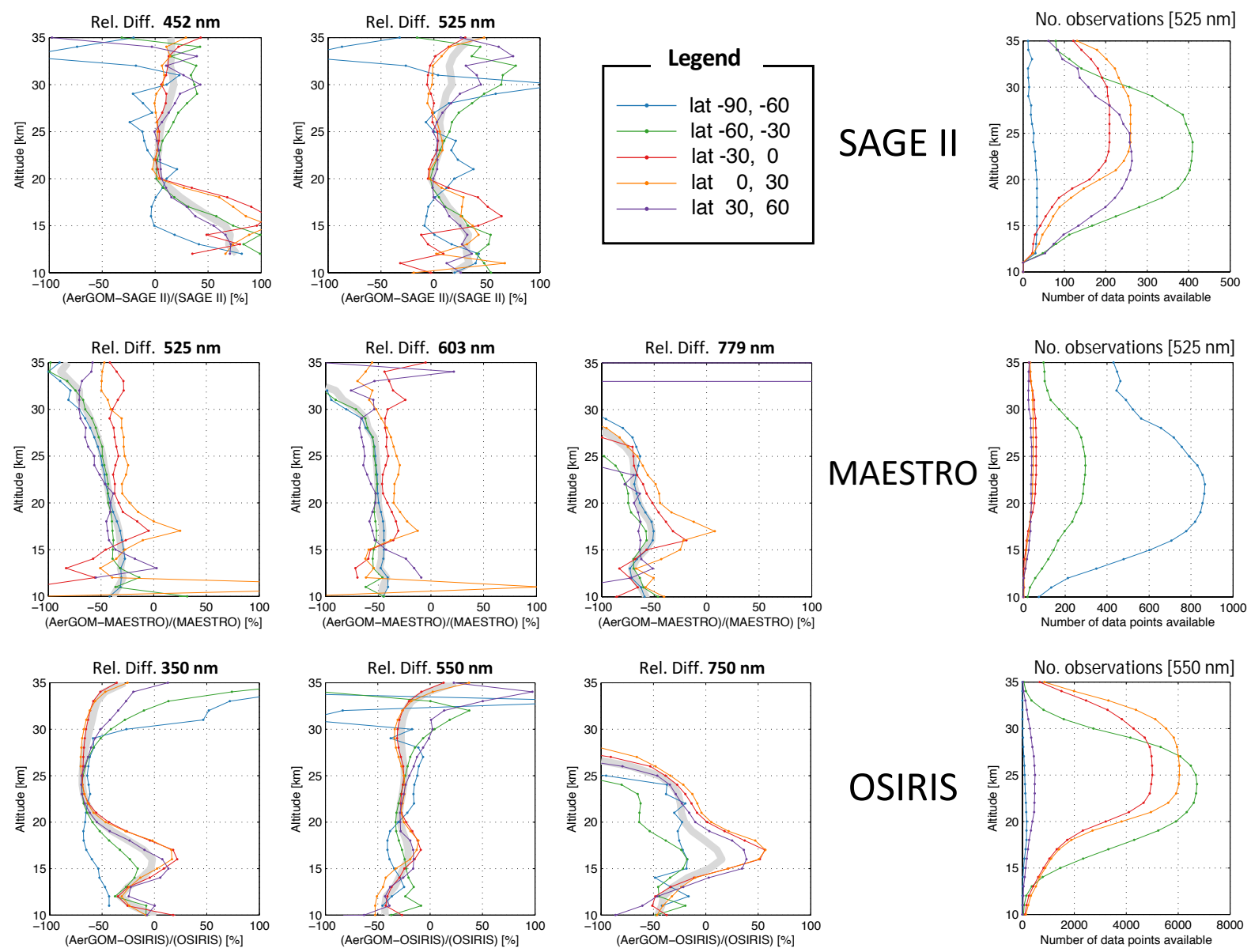

Figure 9. Relative differences between AerGOM and SAGE II, MAESTRO and OSIRIS datasets for different categories of latitudes of occultations, based on $30^{\circ}$ latitude bands (left panels). The rightmost panel presents the number of observations for each comparison and latitude band.

to the stratosphere by cutting off profile information at the tropopause, which effectively work as a cloud filter in the tropics and might explain the positive bias between AerGOM and OSIRIS. For the other datasets, the reason for the fact that AerGOM is more positively biased is unclear.

There is also a marked difference at all altitudes between observations carried out in the tropics and those made at mid to high latitudes. Comparisons with SAGE II show much more variability across the mid-latitude occultations above $20 \mathrm{~km}$. For the MAESTRO comparisons, there is an almost constant bias difference of $25 \%$ between tropical and midlatitude observations at shorter wavelengths. These discrepancies cannot be explained only by a difference in sampling, nor due to the SZA as it was shown that stray-light contamination does not affect AerGOM measurements below $700 \mathrm{~nm}$ significantly. There is also no indication that PSCs have an impact on the comparisons. The AerGOM-OSIRIS comparison at $750 \mathrm{~nm}$ also shows a notable difference for the Southern Hemisphere (latitude $\leq-30^{\circ}$ ) compared with the other latitude bands, with AerGOM data being more nega- tively biased in these cases. This effect is also seen at shorter wavelengths between 12 and $20 \mathrm{~km}$ but to a lesser extent. However, these differences could well be explained by the low SZA values of the observations in these categories, since a majority of observations were made with a SZA $\leq 120^{\circ}$, which was shown to affect the AerGOM larger-wavelength aerosol extinctions significantly.

No results are shown for SAGE III because the collocations with AerGOM were only contained within one latitude band.

\section{Conclusion}

In this study, we compared the results of stratospheric aerosol extinction coefficients retrieved by AerGOM in the UV-Vis with several datasets observing in the same spectral range and during the same period as GOMOS. Overall, the intercomparisons with almost all sensors show an agreement within $\pm 50 \%$ in the $400-600 \mathrm{~nm}$ spectral range, between 20 and $30 \mathrm{~km}$. More specifically, the agreement in this spectral 
and altitude range with SAGE II version 7 and SAGE III version 4.0 is within $\pm 15 \%$ and $\pm 45 \%$, respectively. There is a strong positive bias below $20 \mathrm{~km}$ at $\lambda<700 \mathrm{~nm}$, consistent with the presence of cirrus clouds at these altitudes. It is shown that IPF v6.01 results are not impacted as much under these conditions and are more accurate than AerGOM, despite a much lower precision. Using a different spectral parameterization of the aerosol extinction cross section based on a degree 1 polynomial in $\lambda^{-1}$ can improve the comparison results below $20 \mathrm{~km}$ significantly, and results obtained in this manner show agreement with SAGE II and SAGE III that are on a par with IPF. Due to AerGOM aerosol extinction strong negative bias observed at wavelengths larger than $700 \mathrm{~nm}$ when compared against SAGE III and OSIRIS datasets at altitudes above $25 \mathrm{~km}$, we do not recommend using AerGOM version 1.0 extinction data in this spectral range. The reason for this discrepancy is not clear, but preliminary work suggests a wrong attribution of extinction to aerosol and gases, which could be improved by the use of better trace gas cross sections, especially ozone.

Section 6 covered different aspects of the AerGOM data comparisons with other datasets as they related to the occultation parameters. It was shown that the quality of the retrieval is mainly influenced by the star parameters that directly impact the SNR of the measurement. The dominant parameter is the star magnitude quantifying the strength of the star signal, and we suggest to use a threshold of $M=2.5$ in order to obtain high-quality profiles. Hot stars perform better than cold stars and the recommended threshold is $T=6 \times 10^{3} \mathrm{~K}$. Another important aspect that influences the quality of the retrieval is the SZA. Using a threshold of $110^{\circ}$ gives good-quality results for extinction at $\lambda<700 \mathrm{~nm}$, but at longer wavelengths, one should use a threshold value of $130^{\circ}$. The influence of the latitude of observation on the bias is probably partly related to cloud detection that is not performed yet in AerGOM, in contrast to some of the other algorithms. The signature of cirrus clouds is clearly seen in the tropical region. There is also a difference in the overall bias if one considers tropical observations and mid-latitude occultations that cannot be explained at the moment. No influence of PSCs on the bias has been identified. Finally, the intercomparison between AerGOM and OSIRIS shows a particular behaviour in the $13-17 \mathrm{~km}$ altitude range, with an increasing negative bias polewards. This is probably due to the poor statistics in this case, and to the over-representation of very low values of the SZA and of dim stars in these regions.

These results can prove useful as guidelines to AerGOM data users as they shed light on the aspects of the occultations which might affect the results systematically.

\section{Data availability}

Data for the AerGOM v1.0 processing version are stored in Network Common Data Form version 4 (NetCDF4) format and can be obtained by contacting Christine Bingen (Christine.Bingen@aeronomie.be).

Acknowledgements. This work was supported by a Marie Curie Career Integration Grant within the 7th European Community Framework Programme under grant agreement no. 293560, the European Space Agency as part of the Aerosol_cci project and the Belgian Space Science Office (BELSPO) through the "Chercheur Supplementaire" programme. The AerGom project was financed by the European Space Agency (contract number 22022/OP/I-OL). We would also like to thank the associate editor, the anonymous reviewers and Steffen Dörner, whose comments helped considerably improve this paper.

Edited by: M. Penning de Vries

Reviewed by: S. Dörner and two anonymous referees

\section{References}

Bernath, P. F., McElroy, C. T., Abrams, M. C., Boone, C. D., Butler, C. J., Camy-Peyret, C., Carleer, M., Clerbaux, C., Coheur, P. F., and Colin, R.: Atmospheric Chemistry Experiment (ACE): Mission overview, Geophys. Res. Lett., 32, L15S01, doi:10.1029/2005GL022386, 2005.

Bertaux, J. L., Kyrölä, E., Fussen, D., Hauchecorne, A., Dalaudier, F., Sofieva, V., Tamminen, J., Vanhellemont, F., Fanton d'Andon, O., Barrot, G., Mangin, A., Blanot, L., Lebrun, J. C., Pérot, K., Fehr, T., Saavedra, L., Leppelmeier, G. W., and Fraisse, R.: Global ozone monitoring by occultation of stars: an overview of GOMOS measurements on ENVISAT, Atmos. Chem. Phys., 10, 12091-12148, doi:10.5194/acp-10-12091-2010, 2010.

Bodhaine, B. A., Wood, N. B., and Dutton, E. G.: On Rayleigh optical depth calculations, J. Atmos. Ocean. Techn., 16, 1854-1861, 1999.

Bourassa, A. E., Degenstein, D. A., Gattinger, R. L., and Llewellyn, E. J.: Stratospheric aerosol retrieval with optical spectrograph and infrared imaging system limb scatter measurements, J. Geophys. Res., 112, D10217, doi:10.1029/2006JD008079, 2007.

Damadeo, R. P., Zawodny, J. M., Thomason, L. W., and Iyer, N.: SAGE version 7.0 algorithm: application to SAGE II, Atmos. Meas. Tech., 6, 3539-3561, doi:10.5194/amt-6-3539-2013, 2013.

DeFoor, T. E., Robinson, E., and Ryan, S.: Early lidar observations of the June 1991 Pinatubo eruption plume at Mauna Loa Observatory, Hawaii, Geophys. Res. Lett., 19, 187-190, 2012.

Deshler, T., Hervig, M., Hofmann, D., Rosen, J., and Liley, J. B.: Thirty years of in situ stratospheric aerosol size distribution measurements from Laramie, Wyoming $\left(41^{\circ} \mathrm{N}\right)$, using balloon-borne instruments, J. Geophys. Res., 108, 4167, doi:10.1029/2002JD002514, 2003.

ESA: GOMOS Product Handbook, European Space Agency, 2007.

Hauchecorne, A.: First simultaneous global measurements of nighttime stratospheric $\mathrm{NO}_{2}$ and $\mathrm{NO}_{3}$ observed by Global Ozone Monitoring by Occultation of Stars (GOMOS)/Envisat in 2003, J. Geophys. Res., 110, D18301, doi:10.1029/2004JD005711, 2005.

Hofmann, D., Rosen, J. M., Pepin, T. J., and Pinnick, R. G.: Stratospheric aerosol measurements I: Time variations at northern midlatitudes, J. Atmos. Sci., 32, 1446-1456, 1975. 
Holzer-Popp, T., de Leeuw, G., Griesfeller, J., Martynenko, D., Klüser, L., Bevan, S., Davies, W., Ducos, F., Deuzé, J. L., Graigner, R. G., Heckel, A., von Hoyningen-Hüne, W., Kolmonen, P., Litvinov, P., North, P., Poulsen, C. A., Ramon, D., Siddans, R., Sogacheva, L., Tanre, D., Thomas, G. E., Vountas, M., Descloitres, J., Griesfeller, J., Kinne, S., Schulz, M., and Pinnock, S.: Aerosol retrieval experiments in the ESA Aerosol_cci project, Atmos. Meas. Tech., 6, 1919-1957, doi:10.5194/amt-61919-2013, 2013.

Jäger, H.: Long-term record of lidar observations of the stratospheric aerosol layer at Garmisch-Partenkirchen, J. Geophys. Res., 110, D08106, doi:10.1029/2004JD005506, 2005.

Junge, C., Chagnon, C. W., and Manson, J. E.: A worldwide stratospheric aerosol layer, Science, 133, 1478-1479, doi:10.1126/science.133.3463.1478-a, 1961.

Kent, G. S. and McCormick, M. P.: SAGE and SAM II measurements of global stratospheric aerosol optical depth and mass loading, J. Geophys. Res.-Atmos., 89, 5303-5314, 1984.

Kyrölä, E., Tamminen, J., and Leppelmeier, G.: GOMOS on Envisat: An overview, Adv. Space Res., 33, 1020-1028, 2004.

Kyrölä, E., Tamminen, J., Sofieva, V., Bertaux, J. L., Hauchecorne, A., Dalaudier, F., Fussen, D., Vanhellemont, F., Fanton d'Andon, O., Barrot, G., Guirlet, M., Mangin, A., Blanot, L., Fehr, T., Saavedra de Miguel, L., and Fraisse, R.: Retrieval of atmospheric parameters from GOMOS data, Atmos. Chem. Phys., 10, 1188111903, doi:10.5194/acp-10-11881-2010, 2010.

Kyrölä, E., Blanot, L., Tamminen, J., Sofieva, V., Bertaux, J. L., Hauchecorne, A., Dalaudier, F., Fussen, D., Vanhellemont, F., Fanton d'Andon, O., and Barrot, G.: GOMOS Algorithm Theoretical Basis Document, Tech. Rep. GOM-FMI-TN-040, 2012.

Llewellyn, E. J., Lloyd, N. D., Degenstein, D. A., Gattinger, R. L., Petelina, S. V., Bourassa, A. E., Wiensz, J. T., Ivanov, E. V., McDade, I. C., Solheim, B. H., McConnell, J. C., Haley, C. S., von Savigny, C., Sioris, C. E., McLinden, C. A., Griffioen, E., Kaminski, J., Evans, W. F., Puckrin, E., Strong, K., Wehrle, V., Hum, R. H., Kendall, D. J., Matsushita, J., Murtagh, D. P., Brohede, S., Stegman, J., Witt, G., Barnes, G., Payne, W. F., Piché, L., Smith, K., Warshaw, G., Deslauniers, D.-L., Marchand, P., Richardson, E. H., King, R. A., Wevers, I., McCreath, W., Kyrölä, E., Oikarinen, L., Leppelmeier, G. W., Auvinen, H., Mégie, G., Hauchecorne, A., Lefèvre, F., de La Nöe, J., Ricaud, P., Frisk, U., Sjoberg, F., von Schéele, F., and Nordh, L.: The OSIRIS instrument on the Odin spacecraft, Can. J. Phys., 82, 411-422, 2004.

Lumpe, J. D., Bevilacqua, R. M., Hoppel, K. W., and Randall, C. E.: POAM III retrieval algorithm and error analysis, J. Geophys. Res., 107, 4575, doi:10.1029/2002JD002137, 2002.

Mateshvili, N.: Twilight sky brightness measurements as a useful tool for stratospheric aerosol investigations, J. Geophys. Res., 110, D09209, doi:10.1029/2004JD005512. 2005.

McElroy, C. T., Nowlan, C. R., Drummond, J. R., Bernath, P. F., Barton, D. V., Dufour, D. G., Midwinter, C., Hall, R. B., Ogyu, A., Ullberg, A., Wardle, D. I., Kar, J., Zou, J., Nichitiu, F., Boone, C. D., Walker, K. A., and Rowlands, N.: The ACE-MAESTRO instrument on SCISAT: description, performance, and preliminary results., Appl. Optics, 46, 4341-4356, 2007.

McElroy, C. T., Barton, D. V., nowlan, C. R., and Drummond, J. R.: MAESTRO: The SCISAT UV-Visible-Near IR Instrument, in: The Atmospheric Chemistry Experiment ACE at 10: a Solar Oc- cultation Anthology, edited by: Bernath, P., 81-101, A. Deepak Publishing, Hampton, VA, USA, 2013.

Randall, C. E., Bevilacqua, R. M., Lumpe, J. D., and Hoppel, K. W.: Validation of POAM III aerosols: comparison to SAGE II and HALOE, J. Geophys. Res.-Atmos. (1984-2012), 106, 2752527536, 2001.

Renard, J.-B., Berthet, G., Robert, C., Chartier, M., Pirre, M., Brogniez, C., Herman, M., Verwaerde, C., Balois, J.-Y., Ovarlez, J., Ovarlez, H., Crespin, J., and Deshler, T.: Optical and physical properties of stratospheric aerosols from balloon measurements in the visible and near-infrared domains. ii. comparison of extinction, reflectance, polarization, and counting measurements, Appl. Optics, 41, 7540, doi:10.1364/AO.41.007540, 2002.

Rieger, L. A., Bourassa, A. E., and Degenstein, D. A.: Stratospheric aerosol particle size information in Odin-OSIRIS limb scatter spectra, Atmos. Meas. Tech., 7, 507-522, doi:10.5194/amt-7507-2014, 2014.

Rodgers, C.: Inverse Methods for Atmospheric Sounding: Theory and Practice, vol. 2 of Series on Atmospheric, Oceanic and Planetary Physics, World Scientific, Singapore, 2000.

Sioris, C. E., Boone, C. D., Bernath, P. F., Zou, J., McElroy, C. T., and McLinden, C. A.: Atmospheric Chemistry Experiment (ACE) observations of aerosol in the upper troposphere and lower stratosphere from the Kasatochi volcanic eruption, J. Geophys. Res., 115, D00L14, doi:10.1029/2009JD013469, 2010.

Sofieva, V. F., Kan, V., Dalaudier, F., Kyrölä, E., Tamminen, J., Bertaux, J.-L., Hauchecorne, A., Fussen, D., and Vanhellemont, F.: Influence of scintillation on quality of ozone monitoring by GOMOS, Atmos. Chem. Phys., 9, 9197-9207, doi:10.5194/acp9-9197-2009, 2009.

Solomon, S., Daniel, J. S., Neely, R. R., Vernier, J. P., Dutton, E. G., and Thomason, L. W.: The persistently variable "background" stratospheric aerosol layer and global climate change., Science, 333, 866-870, 2011.

Taha, G., Rault, D. F., Loughman, R. P., Bourassa, A. E., and von Savigny, C.: SCIAMACHY stratospheric aerosol extinction profile retrieval using the OMPS/LP algorithm, Atmos. Meas. Tech., 4, 547-556, doi:10.5194/amt-4-547-2011, 2011.

Thomason, L. W. and Vernier, J.-P.: Improved SAGE II cloud/aerosol categorization and observations of the Asian tropopause aerosol layer: 1989-2005, Atmos. Chem. Phys., 13, 4605-4616, doi:10.5194/acp-13-4605-2013, 2013.

Thomason, L. W., Burton, S. P., Luo, B.-P., and Peter, T.: SAGE II measurements of stratospheric aerosol properties at non-volcanic levels, Atmos. Chem. Phys., 8, 983-995, doi:10.5194/acp-8-9832008, 2008.

Thomason, L. W., Moore, J. R., Pitts, M. C., Zawodny, J. M., and Chiou, E. W.: An evaluation of the SAGE III version 4 aerosol extinction coefficient and water vapor data products, Atmos. Chem. Phys., 10, 2159-2173, doi:10.5194/acp-10-2159-2010, 2010.

Twomey, S.: Introduction to the mathematics of inversion in remote sensing and indirect measurements, Developments in Geomathematics, Elsevier Scientific Pub. Co, New York, USA, 1996.

Vanhellemont, F., Fussen, D., Mateshvili, N., Tétard, C., Bingen, C., Dekemper, E., Loodts, N., Kyrölä, E., Sofieva, V., Tamminen, J., Hauchecorne, A., Bertaux, J.-L., Dalaudier, F., Blanot, L., Fanton d'Andon, O., Barrot, G., Guirlet, M., Fehr, T., and Saavedra, L.: Optical extinction by upper tropospheric/stratospheric aerosols and clouds: GOMOS observations for the period 2002- 
2008, Atmos. Chem. Phys., 10, 7997-8009, doi:10.5194/acp-107997-2010, 2010.

Vanhellemont, F., Mateshvili, N., Blanot, L., Robert, C. É., Bingen, C., Sofieva, V., Dalaudier, F., Tétard, C., Fussen, D., Dekemper, E., Kyrölä, E., Laine, M., Tamminen, J., and Zehner, C.: AerGOM, an improved algorithm for stratospheric aerosol extinction retrieval from GOMOS observations - Part 1: Algorithm description, Atmos. Meas. Tech., 9, 4687-4700, doi:10.5194/amt9-4687-2016, 2016. von Savigny, C., Ernst, F., Rozanov, A., Hommel, R., Eichmann, K.U., Rozanov, V., Burrows, J. P., and Thomason, L. W.: Improved stratospheric aerosol extinction profiles from SCIAMACHY: validation and sample results, Atmos. Meas. Tech., 8, 5223-5235, doi:10.5194/amt-8-5223-2015, 2015. 